\title{
Diurnal Cycle of Renal Hemodynamics and Excretion of Chloride and Potassium in Hypertensive Subjects *
}

\author{
Antonio I. Vagnucci $\dagger$ and Laurence G. Wesson, Jr. $\$$ \\ (From the Department of Medicine, New York University Postgraduate Medical School, \\ New York, N. Y.)
}

Since the experiments of Goldblatt, Lynch, Hanzal, and Summerville (1), the kidney has been a center of interest to students of hypertension. Disturbances of glomerular filtration rate, renal blood flow, and tubular function (2) as well as abnormalities in the excretion of $\mathrm{NaCl}$ (3-9) have been reported in hypertensive persons. Very little information is available, however, concerning the diurnal variations of the renal hemodynamic parameters in hypertensive disease (10); moreover, a review of the literature reveals no data concerning the diurnal changes of the electrolyte excretion in essential hypertension. The present work was undertaken to begin to supply this missing information.

\section{Methods}

The subjects were patients from the Hypertension Clinic of the Outpatient Department of the Fourth Medical Division and from the wards of the Third and Fourth Medical and Surgical Divisions of Bellevue Hospital.

No clinical evidence of congestive heart failure or renal or liver disease was present at the time of the study. The age, sex, race, mean blood pressure before and during the investigation period, and pertinent clinical and laboratory findings are recorded in Table I. No patients showed asymmetrical or abnormal excretion patterns on iv pyelography. All clinical data were consistent with, but not conclusive proof of, the diagnosis of essential hypertension. Patients W. A. and H. A., identical twins, are included because of a well-documented record of hypertension before and after myocardial infarctions. Several higher blood pressure readings were also present in the clinical chart of patient P. W. Routinely, blood

* Submitted for publication June 25, 1963; accepted November 21, 1963.

Supported by grants-in-aid from the American Heart Association and by grant $\mathrm{H}-2172$ from the U. S. Public Health Service.

$\dagger$ Research fellow of the American Heart Association. Present address: Department of Medicine, Peter Bent Brigham Hospital, Boston, Mass.

\$ Present address: Department of Medicine, Jefferson Medical College, Philadelphia, $\mathrm{Pa}$. pressure was somewhat or much lower during residence in the study unit than in the Outpatient Department. Most of the subjects had been receiving no specific treatment ; four (W. A., H. A., P. W., and E. M.) had been on thiazide therapy, but this had been stopped at least 2 weeks before the study.

Each subject was admitted to the Special Clinical Unit of New York University in Bellevue Hospital for an "equilibration" period of 24 to 36 hours. The purpose of this equilibration period was to familiarize patients with the hospital environment and with the experimental routine. In no sense had the patients attained approximate electrolyte or body fluid balance, which would have required more time than most could spare from their work. During this time, urine was collected and vital signs were recorded every 3 hours. The patients were on a self-selected diet at home and on a regular diet if in the hospital. The hospital diet contained approximately $3 \mathrm{~g}$ of $\mathrm{Na}$ and $4 \mathrm{~g}$ of $\mathrm{K}$ with a salt shaker available on the food tray. Fluids were allowed ad libitum.

Details of the procedures followed in measuring the clearances of salt-free inulin ${ }^{1}$ and para-aminohippurate $(\mathrm{PAH})$ are described elsewhere (11). The average duration of the study was 36 hours. Since the infusion was usually started in the late afternoon, the clearance periods between 7 p.m. and 7 a.m. are the means of two periods occurring in consecutive nights. With the exception of two patients (J. C. and D. H.) who had indwelling catheters throughout the investigation, all subjects voided spontaneously. The prostates of the male patients were not enlarged by digital examination. We endeavored to secure as complete a bladder emptying as possible by emphasizing its importance, procuring favorable environmental conditions, and practicing voiding during the equilibration period.

The infusion apparatus allowed freedom of movement within a 10 - to 12 -foot radius from the infusion pump; however, with the exception of patient J. T., who sat or stood up during the day, the patients usually maintained a recumbent or semirecumbent position. Since blood was drawn painlessly through an indwelling venous catheter (Bardic Intracath), the sleep of the patients during the night was minimally disturbed. Chemical analyses, as well as the calculations of the clearance of inulin, $\mathrm{PAH}$, and filtration fraction, were performed as described previously $(11,12)$.

1 Kindly supplied by the General Diagnostics Division, Warner-Chilcott Corp. Morris Plains, N. J. 
TABLE I

Clinical data of 12 hypertensive patients

\begin{tabular}{|c|c|c|c|c|c|c|c|}
\hline \multirow[b]{2}{*}{ Name } & \multirow[b]{2}{*}{ Age } & \multirow[b]{2}{*}{ Sex* } & \multirow[b]{2}{*}{ Race* } & \multirow{2}{*}{$\begin{array}{l}\text { Duration } \\
\text { of hyper- } \\
\text { tension }\end{array}$} & \multicolumn{2}{|c|}{ Mean blood pressure } & \multirow[b]{2}{*}{ Remarks $\ddagger$} \\
\hline & & & & & Before test & During test & \\
\hline J. T. & 33 & $\mathbf{M}$ & $\mathbf{N}$ & $<2.0$ & $200 / 124$ & $178 / 118$ & $\mathrm{EH}$ and ret. absent; FH doubtful \\
\hline E. S. & 45 & $\mathbf{F}$ & $\mathbf{N}$ & 10 & $154 / 108$ & $156 / 102$ & $\begin{array}{l}\text { Menstruating during study; hemato- } \\
\text { crit } 34 \% \text {; ret.I; FH doubtful }\end{array}$ \\
\hline D. H. & 64 & $\mathbf{M}$ & $\mathrm{C}$ & 11 & $180 / 100$ & $172 / 104$ & $\begin{array}{l}\text { Lobectomy for tuberculosis, } 1951 \text {; } \\
\text { EH and ret.I; FH doubtful }\end{array}$ \\
\hline W. A. $\S$ & 55 & $\mathbf{M}$ & W & 10 & $142 / 99$ & $132 / 93$ & $\begin{array}{l}\text { Psoriasis; nephrolithiasis, } 1956 \text {; myo- } \\
\text { cardial infarctions, 1957, 1959; } \\
\text { FH present }\end{array}$ \\
\hline H. A. $\S$ & 55 & $\mathbf{M}$ & W & 10 & $101 / 75$ & $110 / 82 \|$ & $\begin{array}{l}\text { Psoriasis; nephrolithiasis, } 2 \text { myo- } \\
\text { cardial infarctions, 1954; FH } \\
\text { present }\end{array}$ \\
\hline S. M. & 41 & $\mathbf{M}$ & $\mathbf{N}$ & $<2.0$ & $214 / 155$ & $214 / 154$ & $\begin{array}{l}\text { Treated syphilis; chronic alcoholism; } \\
\text { ret. I; FH present }\end{array}$ \\
\hline K. G. & 51 & $\mathbf{M}$ & W & $<1.0$ & $167 / 106$ & $152 / 104$ & $\mathrm{EH}$ and ret. absent; FH doubtful \\
\hline J. C. & 64 & $\mathbf{M}$ & W & 7 & $158 / 94$ & $158 / 108$ & $\begin{array}{l}\text { Night watchman; EH and ret.I: } \\
\text { FH absent }\end{array}$ \\
\hline J. J. & 44 & $\mathbf{M}$ & $\mathrm{N}$ & 20 & $200 / 142$ & $180 / 132$ & $\begin{array}{l}\text { Diabetes mellitus, known duration, } \\
1 \text { month; EH and ret.I; FH absent }\end{array}$ \\
\hline L. S. & 40 & $\mathbf{M}$ & $\mathrm{N}$ & $<1.0$ & $156 / 95$ & $130 / 88$ & $\begin{array}{l}\text { Chronic alcoholism; EH and ret.I ab- } \\
\text { sent; FH doubtful }\end{array}$ \\
\hline P. W. & 38 & $\mathrm{~F}$ & $\mathrm{~N}$ & $?$ & $156 / 102$ & $128 / 88$ & $\begin{array}{l}\text { Mastectomy and irradiation castra- } \\
\text { tion, 1958; } \mathrm{EH} \text { and ret. I absent; } \\
\text { FH present }\end{array}$ \\
\hline E. M. & 57 & M & W & 6 & $186 / 117$ & $169 / 118$ & $\begin{array}{l}\text { Amputation left forearm, traumatic; } \\
\text { EH; FH absent }\end{array}$ \\
\hline
\end{tabular}

* $\mathrm{M}=$ male, $\mathrm{F}=$ female, $\mathrm{C}=$ Chinese, $\mathrm{N}=$ Negro, and $\mathrm{W}=$ white.

+ Documented duration, in years.

$\ddagger \mathrm{EH}=$ moderate to marked clinical enlargement of the heart; ret.I = grade I retinopathy (Keith-Waggoner); $\mathrm{FH}=$ family history.

Identical twins.

Korotkoff sounds were not clear.

TABLE II

Maximal, minimal, and average values of the glomerular filtration rate, renal plasma flow, and fultration fraction during the diurnal cycle in 12 hypertensive subjects

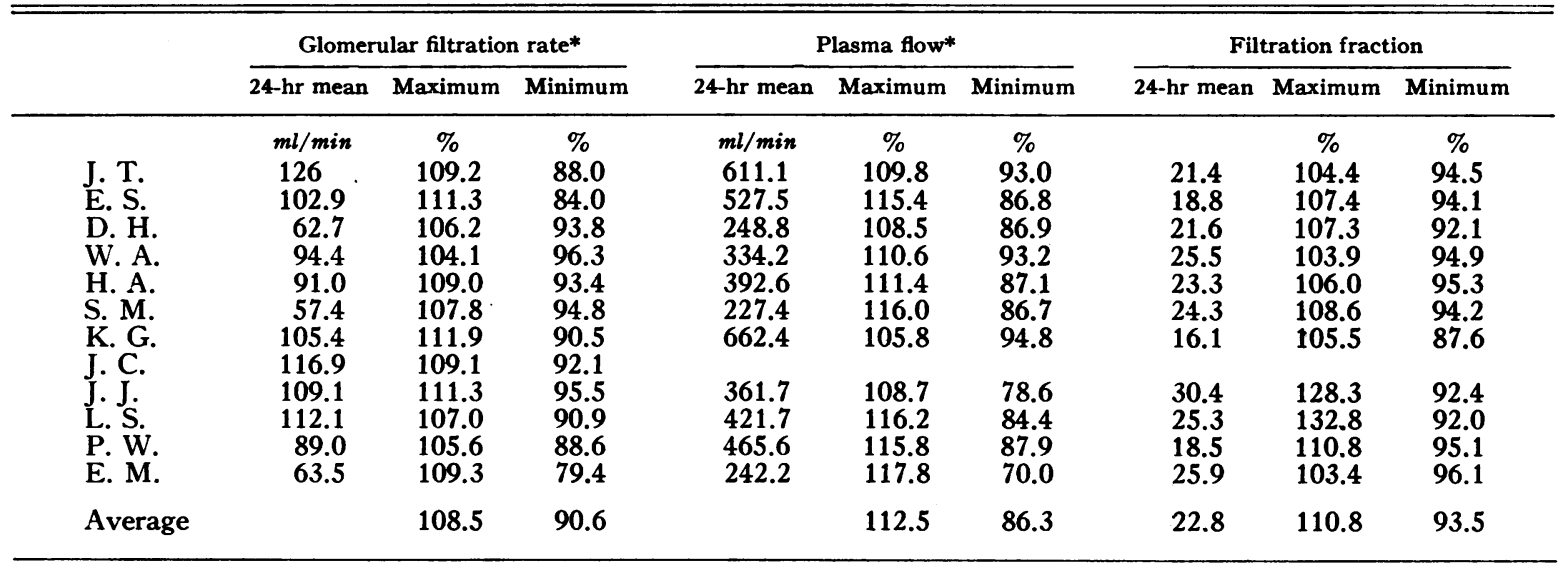

* In $\mathrm{ml}$ per minute per $1.73 \mathrm{~m}^{2}$. 


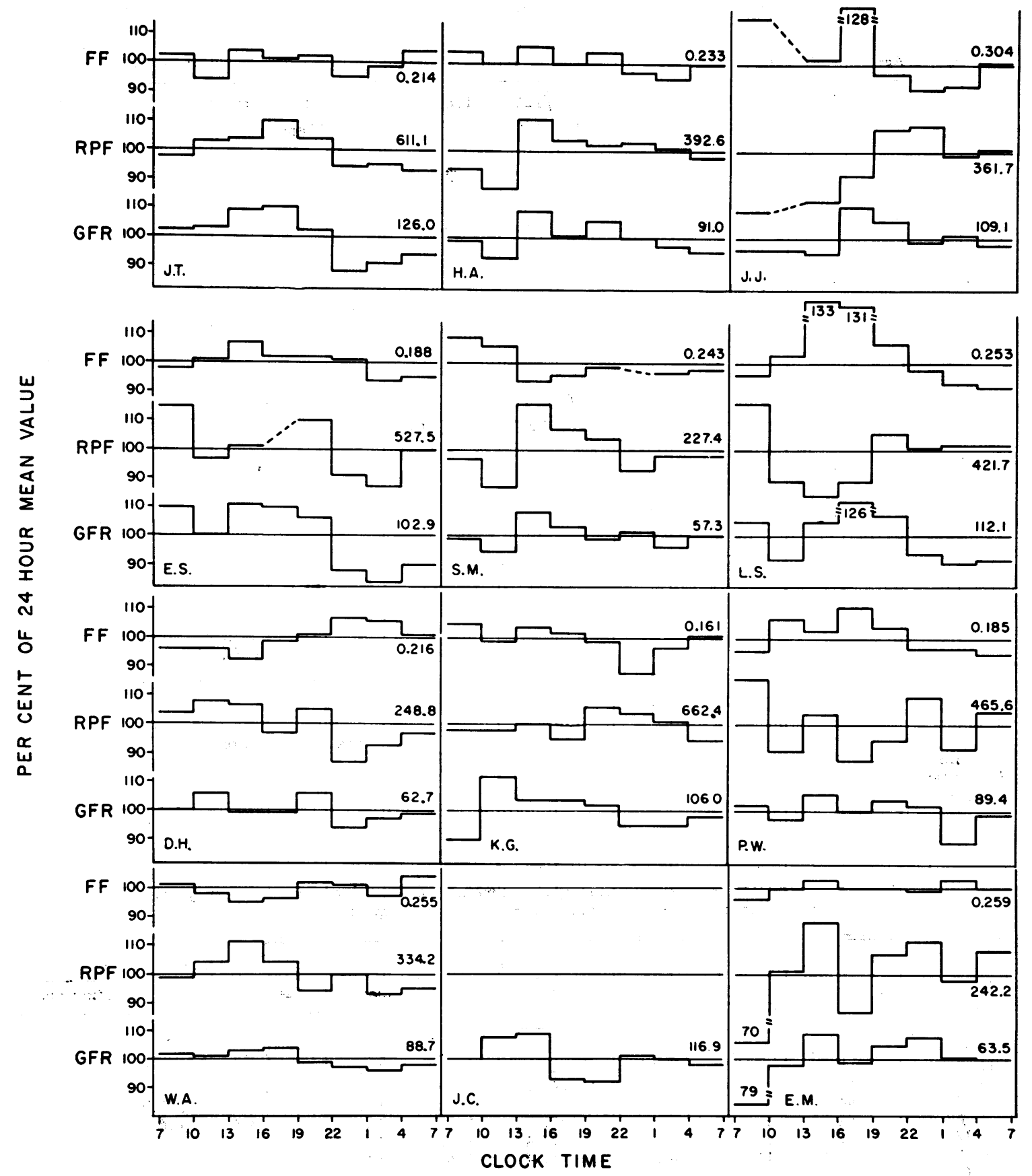

Fig. 1. Diurnal cycles of glomerular filtration rate (GFR), effective renal plasma flow (RPF), AND FILTRATION FRACTION (FF) OF 12 HYPERTENSIVE SUBJECTS REPRESENTED AS PERCENTAGE OF DEVIATION FROM THEIR 24-HOUR MEAN values (numbers above the lines marking the absolute values). GFR and RPF are corrected to $1.73 \mathrm{~m}^{2}$ of body surface area. 
GROUP I

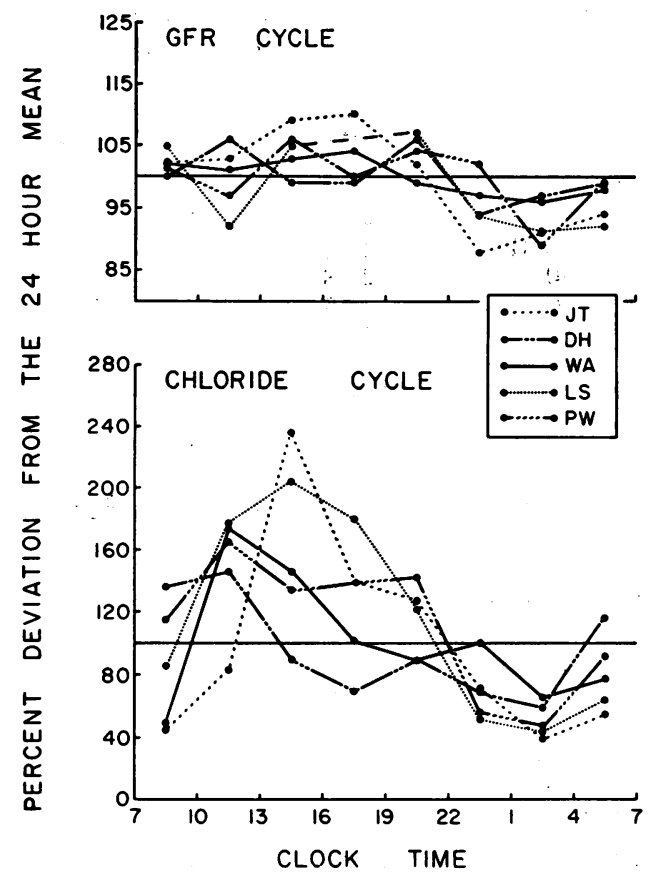

GROUP II

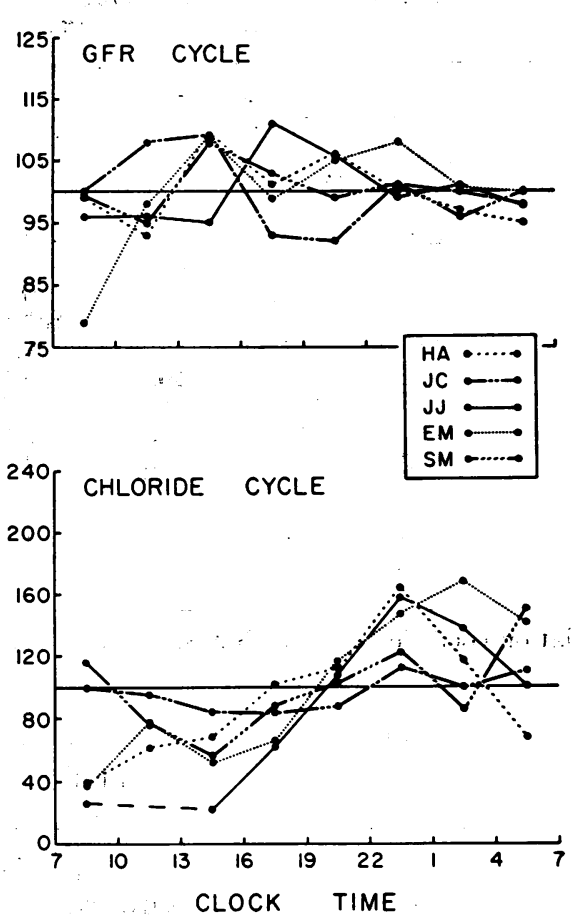

Fig. 2. Comparison of THE GFR CyCles - With THE CORRESPONDING Chloride (CL) CyCles IN PATIENTS OF GRoups I (left side of the figure) AND II (right side). See text for method of grouping. The cycles of two patients (E. S. and K. G.) belonging to group I have been omitted to avoid overloading the figure.

\section{Results}

\section{Renal hemodynamics}

The diurnal cycles of inulin and $\mathrm{PAH}$ clearances and of the filtration fraction are illustrated in Figure 1. No definite diurnal variation of blood pressure readings was observed. This contrasts with several reports that a variation is present in normal and hypertensive subjects (13-17). This line of investigation was not pursued, and a diurnal rhythm might have been revealed by more intensive measurements. "The diurnal cyclè of the body temperature was within normal limits, showing a minimum between 1 and 7 a.m. and a maximum between 1 and 4 p.m. for most subjects. The cycles of two subjects (J. T. and $\because D . H$. ) were about 3 hours earlier and in three subjects (L. S., K. G., and J. J:) could not be distinguished.

Filtration rate. The average amplitude of the diurnal cycle of the GFR, measured as the difference between the maximal and the minimal percentile deviation from the 24-hour mean, was
$18 \%$. Range for the minimum was 79 to $96 \%$ and for the maximum, 104 to $112 \%$ (Table II). The individual and average values of the amplitude of the cycles did not differ greatly from those reported for healthy subjects (11).

Seven of the twelve patients (Figure 1) showed nighttime minima (periods between 10 p.m. and 4 a.m.) as described in the normals (11). ${ }^{2}$ For these patients the trend of the daytime values was

2 Two studies $(11,18)$ on normotensive subjects are used for comparison, - Sirota, Baldwin, and Villarreal (18) studied a group of male subjects with an average age of 40 years drawn from a population similar to the present group of hypertensive subjects. Wesson (11) studied a group of nonhospitalized male and female subjects with an average age of 25 years. Bath age groups are in good agreement with respect to the phase of the hemodynamic cycles, but the amplitudes of the cycles were significantly greater in the latter group. Since neither study shows any evidence of an age-correlated variation in amplitude between 20 and 50 years, the differences between the two studies seem reasonably attributable to differences in technique. No sex-correlated etfferences in the cycles have been detected $\cdot(11)$. 


\section{TABLE III}

Maximal, minimal, and average values of the chloride and potassium excretion rates during the diurnal cycle in 12 hypertensive subjects

\begin{tabular}{|c|c|c|c|c|c|c|c|c|c|}
\hline \multirow[b]{2}{*}{ Subject } & \multicolumn{4}{|c|}{ Chloride excretion } & \multirow[b]{2}{*}{$\mathrm{r}^{*}$} & \multicolumn{4}{|c|}{ Potassium excretion } \\
\hline & $\begin{array}{l}\text { 24-hr } \\
\text { mean }\end{array}$ & Maximum & Minimum & $\begin{array}{c}\text { Mean } \\
\text { plasma } \\
\mathrm{Cl}\end{array}$ & & $\begin{array}{l}24-\mathrm{hr} \\
\text { mean }\end{array}$ & Maximum & Minimum & $\begin{array}{c}\text { Mean } \\
\text { plasma } \\
\mathbf{K}\end{array}$ \\
\hline & $\mu E q / \min$ & $\%$ & $\%$ & $m E q / L$ & & $\mu E q / \min$ & $\%$ & $\%$ & $m E \boldsymbol{q} / L$ \\
\hline J. T. & 72.9 & 238.0 & 40.3 & 101.8 & +0.360 & 41.2 & 202.2 & 59.2 & 3.9 \\
\hline E. S. & 71.8 & 240.5 & 9.7 & 100.8 & +0.370 & 41.9 & 155.6 & 62.5 & 3.7 \\
\hline D. H. & 10.1 & 146.5 & 59.4 & 107.6 & +0.263 & 26.8 & 141.7 & 84.7 & 3.4 \\
\hline W. A. & 21.3 & 173.2 & 50.7 & 108.7 & +0.293 & 16.5 & 149.7 & 85.4 & 3.9 \\
\hline H. A. & 55.4 & 165.2 & 40.2 & 110.7 & -0.138 & 43.2 & 151.2 & 81.7 & 4.1 \\
\hline S. M. & 137.2 & 151.9 & 56.1 & 107.8 & -0.382 & 60.8 & 138.6 & 74.1 & 3.8 \\
\hline K. G. & 41.6 & 141.8 & 63.0 & 105.5 & +0.08 & 41.0 & 129.8 & 74.1 & 4.1 \\
\hline J. C. & 76.6 & 113.2 & 83.0 & 110.6 & +0.001 & 35.3 & 109.6 & 77.6 & 3.8 \\
\hline J. J. & 110.1 & 156.9 & 22.7 & 96.5 & -0.209 & 41.6 & 129.5 & 75.9 & 3.1 \\
\hline L. S. & 120.4 & 203.4 & 43.5 & 103.0 & +0.682 & 34.3 & 175.2 & 62.9 & 3.6 \\
\hline P. W. & 48.4 & 164.9 & 48.3 & 113.9 & +0.501 & 30.9 & 161.2 & 68.3 & 3.6 \\
\hline E. M. & 129.3 & 168.1 & 37.4 & 110.5 & +0.030 & 45.3 & 153.0 & 35.8 & 3.3 \\
\hline
\end{tabular}

${ }^{*}$ Correlation coefficient $\Delta \mathrm{Cl}$ with $\Delta \mathrm{GFR}$; calculation as described in the test.

above the 24-hour mean. The diurnal variation of the glomerular filtration rate (GFR) in the remaining five was less uniform. The minimum for all but patient $\mathrm{J}$. C. appeared in the three periods between 7 a.m. and 4 p.m.) ; ${ }^{3}$ a downward slope was observable during the hours 1 to 7 a.m. (right side of the graph in Figure 2), a downward trend more evident in some (H. A., S. M.) than in others and continuing into the late part of the forenoon. Patient J. C., a night watchman, differed in that the lowest point of the GFR shifted to between 4 p.m. and 10 p.m. As will be seen below, this latter group of subjects also showed changes in the $\mathrm{Cl}$ excretion cycle.

Many of the 24-hour mean values of the GFR were below the expected normal even after allowance was made for the decline due to age (19).

Renal plasma flow (ERPF). The difference between the average minimal and maximal amplitude of all the patients was $26.2 \%$. Range for the minimal values was 70 to $95 \%$; for the maximal values, 106 to $118 \%$ (Table II). As observed in the case of GFR, the individual and averaged amplitudes of ERPF were similar to the normal (11). Most of the subjects showed a fair degree of synchronization between the cycles

3 "Daytime" is considered the interval between 7 a.m. and 10 p.m.; "nighttime," the period between 10 p.m. and 7 a.m. This division is roughly equivalent to the average activity-sleep routine of our subjects. of GFR and ERPF (Figure 1). The heterogeneity of the population of this study discouraged averaging of all the data, as can be done for the normals (11), so that a more detailed comparison of the phase relationship between the two cycles was not feasible. In subjects $K$. G. and L. S., inspection of the graph (Figure 1) shows shift of phase between inulin clearance $C_{\text {In }}$ and $C_{\mathbf{P A B}}$ of approximately $180^{\circ}$, whereas $\mathrm{C}_{\mathbf{P A B}}$ in patient P. W. fluctuated irregularly around the 24-hour mean. The 24-hour mean $p$-aminohippurate clearance was markedly depressed in $75 \%$ of the patients and appeared to be the first to suffer from the hypertensive disease (2).

Filtration fraction (FF). All except three patients (E. S., K. G., and P. W.) had an elevation of $\mathrm{FF}$, a finding previously observed for the hypertensive population (2). Since the diurnal changes of the GFR and RPF did not parallel each other as to magnitude and, in some cases, also as to phase, cyclical fluctuations of FF around the mean were observed frequently.

\section{Electrolyte excretion}

Chloride excretion. The total 24-hour $\mathrm{Cl}$ excretion ranged between 50 and 100 mmoles for most of the subjects. For two of them (D. H. and W. A.), excretion was 15 and 31 mmoles, respectively, whereas in four patients (J. J., L. S., E. M., and S. M.) the excretion was 150 to 200 mmoles per 24 hours. From analysis of the elec- 
trolyte excretion during the equilibration period, the chloruresis caused by restriction of activity appeared extinguished in the majority of the hypertensives after about 12 hours. Thus we feel that the measured 24-hour $\mathrm{Cl}$ excretion may be a fair estimate of the average excretion preceding the study. The contours of the $\mathrm{Na}$ excretion cycles paralleled those of the $\mathrm{Cl}$ cycles very closely in all subjects.

For most of the patients, the rate of $\mathrm{Cl}$ excretion during a 24-hour period varied between $150 \%$ and $50 \%$ of the 24 -hour mean (Table III). Some of the subjects (E. S., J. T., and L. S.) exhibited an even greater amplitude, but amplitude was small in the case of patient J. C. Self-imposed salt restriction on the part of patient D. L. failed to suppress his diurnal excretion cycle, a finding in agreement with previous observations in normals $(12,20)$.

Maximal chloride excretion rate occurred during the daytime in seven subjects and during the night in five subjects. This shift of phase of the cycle by nearly $180^{\circ}$ in about half our subjects is seen more clearly in Figure 2. We shall henceforth designate the subjects with the daytime maximum as group $\mathrm{I}$ and the patients with nighttime maximal $\mathrm{Cl}$ excretion rate as group II. The simultaneously measured GFR cycles are also shown in Figure 2 in such a way that the excretion and filtration cycles may be compared.

The maxima and the minima of the two rhythms clearly occurred as close to simultaneously in group I as methods permit us to determine, and these rhythms are indistinguishable from those of a normotensive population (11). No such correlation appears to exist in group II, however. In this group, although chloride excretion is, by definition, maximal at night, the GFR cycles exhibited no correspondence of phase or consistent pattern. The relationship between $\mathrm{Cl}$ excretion and GFR in the two groups of hypertensive patients can be shown in two more ways. The difference in $\mathrm{Cl}$ excretion between one period and its preceding one has been compared with the simultaneous period-to-period differences in GFR; the correlation coefficients of these paired values for each patient are listed in Table III. A positive correlation ( $r=0.263$ to 0.682 ) between GFR and $\mathrm{Cl}$ excretion was evident for all patients of group $I$ with the exception of patient K. G. $(r=0.08)$. The mean correlation $(r=0.364)$ for the group is highly significant. Among the patients of group II, however, the coefficients of correlation shown in Table III between period-to-period changes in chloride excretion and in GFR were close to or less than zero, and the group mean $(r=-0.139)$

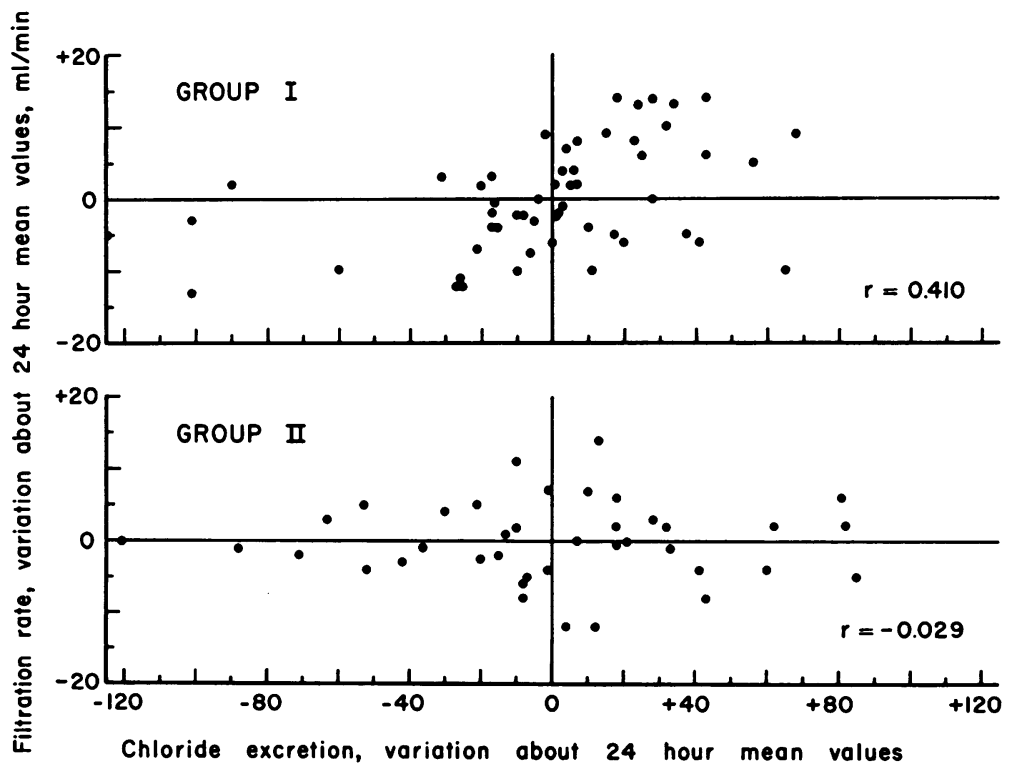

Fig. 3. Correlation between GFR and Cl excretion in each ClearANCE PERIOD OF GROUPS I AND II MEASURED AS DEVIATIONS FROM THEIR 24hOUR MEAN VALCES (expressed in micromoles per minute). 
GROUP I

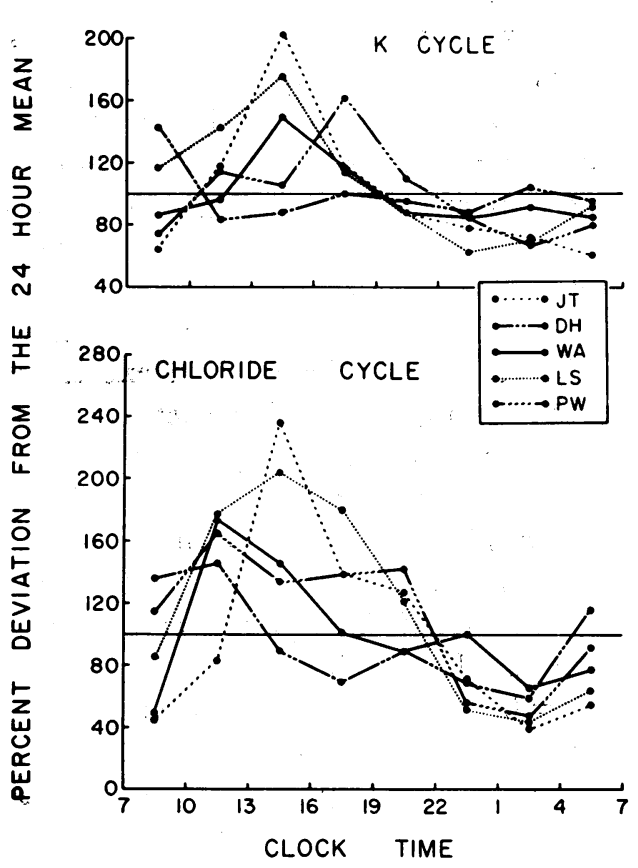

GROUP II

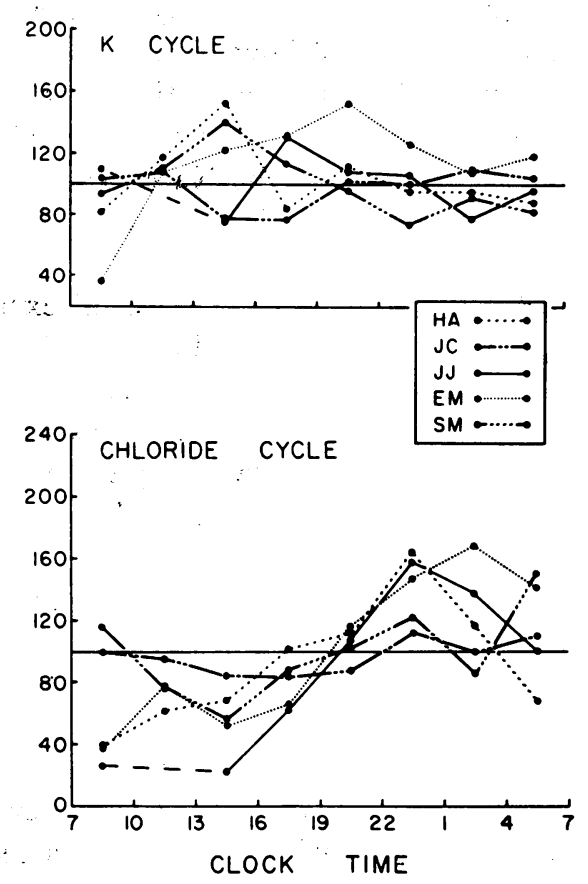

Fig. 4. Comparison of the $\mathrm{K}$ CyCles of groups i and il With the corresponding $\mathrm{Cl}_{\mathrm{L}}$ CyCles.

is not significant. The relationship between GFR and $\mathrm{Cl}$ excretion can also be measured by the distribution of paired values around their 24-hour means. The distributions of these pairs for the patients of groups I and II are shown in Figure 3. The correlation is positive and significant for group I but not significant for group II.

The plasma chloride concentration in each individual did not vary from the 24 -hour mean more than 2 mmoles per L.

Potassium excretion. Pertinent data are given in Table III and Figure 4. The following conclusions may be drawn: 1) no significant diurnal variation of the plasma $K$ was observed, 2) the amplitude of the $\mathrm{K}$ cycle was generally less than for the $\mathrm{Cl}$ excretion cycle, and 3) the peak of excretion for most of the $K$ cycles was close to midday both in group I and group II (Figure 4). Figure 4 also shows the dissociation of the excretion cycles of $\mathrm{K}$ and $\mathrm{Cl}$ in the patients with nocturnal chloruresis (group II). Only in patients J. C. and E. M. do the peaks of the K excretion cycle appear to have shifted in the direction of the $\mathrm{Cl}$ cycle.

\section{Discussion}

Periodic phenomena are described by three primary parameters. 1) The period is the interval of time at the end of which the phenomenon repeats itself. The studies of Lewis and Lobban (21) indicate that the intrinsic period of healthy adult human excretory patterns is indistinguishable from 24 hours. Our experiments were not designed to measure the intrinsic period in hypertensive subjects. 2) Amplitude is the difference between maximum and minimum. The amplitudes of the several variables studied in hypertensive subjects showed no significant differences from the corresponding values in normotensives. 3) The phase is the time interval by which a rhythmic event precedes or follows another one. Finally, the contour, which encompasses all remaining information, cannot be examined quantitatively in these studies.

The particular term in which many of these hypertensive patients appeared to differ from healthy subjects was in the phase of their renal functions. In the normotensives (11) GFR 
showed a minimum between 1 and 4 a.m.; simultaneously, the $\mathrm{Cl}$ cycle attained its lowest point. Figure 2 shows that hypertensive subjects of group I were similar, although two subjects included in this "normal" group differed from normotensives in showing a phase shift of RPF. In group II, however, the phase of the $\mathrm{Cl}$ cycle shifted approximately $180^{\circ}$ from the normal. A corresponding phase shift of the inulin clearance cycle was not evident, although a flattening of the cycle occurred. The significance of this phase shift is obscure. Reversal of the diurnal cycle of renal sodium or chloride excretion has been reported in cirrhosis of the liver $(22,23)$, in congestive heart failure (23-25), in hypertension (26), glomerulonephritis $(23,26)$, nephrosis $(27)$, Cushing's disease (28), primary hyperaldosteronism (29), obesity or head injury (30), and after inversion of the sleep-activity routine $(31,32)$. GFR has been measured in two of these conditions. In congestive heart failure $(24,25)$ and cirrhosis (22), day and night measurements suggest that the GFR cycle also is reversed and that synchrony between the GFR and the chloride excretion cycles is maintained. Such a pattern, if confirmed, is clearly different from our group II hypertensive patients.

Renal function as measured by $\mathrm{C}_{\text {In }}$ and $\mathrm{C}_{\mathbf{P A H}}$ was extensively depressed in some of the hypertensive subjects (S. M. and E. M.) with abnormal cycle. Renal functional impairment did not, however, appear to be a necessary functional correlate with cycle reversal, since other subjects with "inverted" cycle had essentially normal GFR, whereas one patient (D. H.) with normal cycle had significant depression of clearances. Although patient $J$. C. was a night watchman with cycle reversal probably correlated to reversal of the sleep-activity cycle, the remaining subjects of group II had the sleep-activity routine of the average population.

Because many of the conditions in which reversal of the renal cycle has been reported are characterized by primary or secondary hyperaldosteronism (33-35), the question of a possible role of this hormone is raised. Some of the patients in our study had low plasma $\mathrm{K}$ (Table III). Biron and associates (36) and Davis and co-workers $(37,38)$ have shown that the renin-angiotensin system may be an important determinant of aldosterone secretion by the adrenals. An increased renin content in the kidney of hypertensive humans and animals (39) has been reported. Genest, Koiw, Nowaczynski, and Leboeuf (40), examining a population of patients with benign hypertension; reported a significant increase of aldosterone excretion in most, but this finding was not confirmed by Laragh and associates (41). A primary role of increased aldosterone secretion in causing reversal of the cycle is doubtful when we consider that increased secretion is present during dietary deprivation of $\mathrm{Na}(42-44)$, a situation in which the diurnal cycle of $\mathrm{NaCl}$ excretion is known to be normal $(12,20)$. Future experiments may, however, demonstrate significant changes in the diurnal cycle of aldosterone secretion.

The reason for the reversal of the $\mathrm{Cl}$ cycle in the patients of group II is unknown. The shift of phase of the GFR cycle may contribute to the $\mathrm{Cl}$ cycle reversal, but in this study shift in $\mathrm{C}_{\text {In }}$ appeared to lag behind the $\mathrm{Cl}$ cycle, and the correlation is poor. De Vries and co-workers propose that phase shift of the sodium chloride cycle occurs in the presence of or as a result of circulatory insufficiency (27), but the mechanisms through which insufficiency affects the cycle remain unknown.

The dissociation between the $\mathrm{K}$ cycle and the $\mathrm{Cl}$ cycle in patients of group II is significant (Figure 4). Lobban in her studies of renal excretion within the framework of a 22- and 27-hour routine has pointed out the lesser susceptibility of the $\mathrm{K}$ cycle than of the $\mathrm{Cl}$ cycle to suffer a shift of phase (45). Information relative to this electrolyte in nocturnal natriuretic states is meager. In a few published studies $(28,30)$, phase shifts in the $K$ cycle follow those in $\mathrm{Na}$ and $\mathrm{Cl}$, but others have observed a persistently normal $\mathrm{K}$ cycle in the presence of an abnormal Na cycle (27). Possible explanations of mechanisms determining the $\mathrm{K}$ cycle (11) as well as relationships between $\mathrm{K}$ and hypertension (46) have been discussed elsewhere.

\section{Summary}

The diurnal variations of glomerular filtration rate and renal plasma flow (GFR and RPF) and of chloride and potassium excretion have been investigated in twelve randomly selected patients with probable essential hypertension. 
Seven patients showed a nocturnal depression of the GFR and of $\mathrm{Cl}$ and $\mathrm{K}$ excretion with $\mathrm{RPF}$ changing nearly pari passu with GFR in most of them. A diurnal rhythm in filtration fraction was usually present. The phase and amplitude of these cycles did not differ significantly from those in normotensives. GFR changes were significantly correlated with chloride excretion changes.

Five patients exhibited a reversal of the $\mathrm{Cl}$ cycle with peak rate of $\mathrm{Cl}$ excretion occurring at night. GFR cycle in these patients was flattened, and its phase may have been slightly retarded, but it was clearly out of phase with the chloride cycle. Changes in GFR were not significantly correlated with chloride excretion. The RPF cycle closely paralleled the GFR cycle. No correlation was noted between phase shift and degree of impairment of renal function.

The $\mathrm{K}$ cycle exhibited the normotensive pattern with maximal excretion in the daytime in all subjects.

\section{References}

1. Goldblatt, H., J. Lynch, R. F. Hanzal, and W. W. Summerville. Studies on experimental hypertension: I. Production of persistent elevation of systolic blood pressure by means of renal ischemia. J. exp. Med. 1934, 59, 347.

2. Goldring, W., H. Chasis, H. A. Ranges, and H. W. Smith. Effective renal blood flow in subjects with essential hypertension. J. clin. Invest. 1941, 20, 637.

3. Baldwin, D. S., A. W. Biggs, W. Goldring, W. H. Hulet, and $\mathrm{H}$. Chasis. Exaggerated natriuresis in essential hypertension. Amer. J. Med. 1958, 24, 893.

4. Hollander, W., and W. E. Judson. Electrolyte and water excretion in arterial hypertension. I. Studies in non-medically treated subjects with essential hypertension. J. clin. Invest. 1957, 36, 1460.

5. Papper, S., J. L. Belsky, and K. H. Bleifer. The response to the administration of an isotonic sodium chloride-lactate solution in patients with essential hypertension. J. clin. Invest. 1960, 39, 876.

6. Brodsky, W. A., and H. N. Graubarth. Excretion of water and electrolytes in patients with essential hypertension. J. Lab. clin. Med. 1953, 41, 43.

7. Thompson, J. E., T. F. Silva, D. Kinsey, and R. H. Smithwick. The effect of acute salt loads on the urinary sodium output of normotensive and hypertensive patients before and after surgery. Circulation 1954, 10, 912.

8. Brown, J. J., and W. S. Peart. The effect of angiotensin on urine flow and electrolyte excretion in hypertensive patients. Clin. Sci. 1962, 22, 1.
9. Biron, P., M. Chretien, and K. Koiw. Effects of angiotensin infusions on aldosterone and electrolyte excretion in normal subjects and patients with hypertension and adrenocortical disorders. Brit. med. J. 1962, 1, 1569.

10. Brod, J., and V. Fencl. Diurnal variations of systemic and renal hemodynamics in normal subjects and in hypertensive disease. Cardiologia (Basel) 1957, 31, 494.

11. Wesson, L. G., Jr. Electrolyte excretion in relation to diurnal cycles of renal function, plasma electrolyte concentrations and aldosterone secretion before and during salt and water balance changes in normotensive subjects. Submitted for publication.

12. Wesson, L. G., Jr., and D. P. Lauler. Diurnal cycle of glomerular filtration rate and sodium and chloride excretion during responses to altered salt and water balance in man. J. clin. Invest. 1961, 40, 1967.

13. Blankenhorn, M. A., and H. E. Campbell. The effects of sleep on blood pressure. Amer. J. Physiol. 1925, 74, 115.

14. Brooks, H., and J. H. Caroll. A clinical study of the effect of sleep and rest on blood pressure. Arch intern. Med. 1912, 10, 97.

15. Málek, J., K. Suk, M. Břešták, and V. Malý. Daily rhythm of leukocytes, blood pressure, pulse rate, and temperature during pregnancy. Ann. N. Y. Acad. Sci. 1962, 98, 1018.

16. Mueller, S. C., and G. E. Brown. Hourly rhythms in blood pressure in persons with normal and elevated pressures. Ann. intern. Med. 1930, 3, 1190.

17. Brown, G. E. Daily and monthly rhythm in the blood pressure of a man with hypertension: a three-year study. Ann. intern. Med. 1930, 3, 1177.

18. Sirota, J. H., D. S. Baldwin, and H. Villarreal. Diurnal variations of renal function in man. J. clin. Invest. 1950, 29, 187.

19. Wesson, L. G., Jr. Glomerular and tubular factors in the renal excretion of sodium chloride. Medicine (Baltimore) 1957, 36, 281.

20. Stanbury, S. W., and A. E. Thomson. Diurnal variations in electrolyte excretion. Clin. Sci. 1951, 10, 267.

21. Lewis, P. R., and Mary L. Lobban. The effects of prolonged periods of life on abnormal time routines upon excretory rhythms in human subjects. Quart. J. exp. Physiol. 1957, 42, 356.

22. Jones, R. A., G. O. McDonald, and J. H. Last. Reversal of diurnal variation in renal function in cases of cirrhosis with ascites. J. clin. Invest. 1952, 31, 326.

23. Goldman, R. Studies in diurnal variation of water on electrolytes: nocturnal diuresis of water and sodium in congestive cardiac failure, cirrhosis of the liver and degenerative glomerulonephritis (abstract). J. clin. Invest. 1951, 30, 642.

24. Baldwin, D. S., J. H. Sirota, and H. Villareal. Diurnal variations of renal function in congestive 
heart failure. Proc. Soc. exp. Biol. (N. Y.) 1950, 74, 578.

25. Brod, J., and Z. Fejfar. The origin of edema in heart failure. Quart. J. Med. 1950, 19, 187.

26. Fishberg, A. Hypertension and Nephritis, 5th ed. Philadelphia, Lee and Febiger, 1954, p. 810.

27. De Vries, L. A., S. P. Ten Holt, J. J. Van Daatselaar, A. Mulder, and J. G. G. Borst. Characteristic renal excretion patterns in response to physiological, pathological and pharmacological stimuli. Clin. chim. Acta 1960, 5, 915.

28. Doe, R. P., J. A. Vennes, and E. B. Flink. Diurnal variation of 17-hydroxycorticoids, sodium, potassium, magnesium and creatinine in normal subjects and in cases of treated adrenal insufficiency and Cushing's syndrome. J. clin. Endocr. 1960, 20, 253.

29. Lennon, E. J., P. P. Ruetz, and W. W. Engstrom. Reversal of diurnal rhythm in excretion of water and salt in primary hyperaldosteronism. Amer. J. Med. 1961, 30, 475.

30. Payne, R. W., and H. E. De Wardener. Reversal of urinary diurnal rhythm following head injury. Lancet 1958, 1, 1098.

31. Norn, M. Untersuchungen über das Verhalten des Kaliums in Organismus. II Uber Schwankungen der Kalium-, Natrium and Chloridausscheidung durch die Niere im Laufe des Tages. Skand. Arch. Physiol. 1929, 55, 184.

32. Sharp, G. W. G. Reversal of diurnal rhythms of water and electrolyte excretion in man. J. Endocr. 1960, 21, 97.

33. Chart, J. J., and E. S. Shipley. The mechanism of sodium retention in cirrhosis of the liver (abstract). J. clin. Invest. 1953, 32, 560.

34. Axelrod, B. J., J. E. Cates, B. B. Johnson, and J. A. Luetscher, Jr. Aldosterone in urine of normal man and of patients with edema: its increased recovery after hydrolysis with acid and betaglucuronidase. Brit. med. J. 1955, 1, 196.

35. Dyrenfurth, I., C. H. Stacey, J. C. Beck, and E. H. Venning. Aldosterone excretion in patients with cirrhosis of the liver. Metabolism 1957, 6, 544.
36. Biron, P., K. Koiw, W. Nowaczynski, J. Brouillet, and J. Genest. The effects of intravenous infusion of valine-5-angiotensin II and other pressor agents on urinary electrolytes and corticosteroids, including aldosterone. J. clin. Invest. 1961, 40, 338.

37. Davis, J. O., P. M. Hartroft, E. O. Titus, C. J. Carpenter, C. R. Ayers, and H. E. Spiegel. The role of the renin-angiotensin system in the control of aldosterone secretion. J. clin. Invest. 1962, 41, 378.

38. Carpenter, C. J., J. O. Davis, and C. R. Ayers. Relation of renin, angiotensin II, and experimental renal hypertension to aldosterone secretion. J. clin. Invest. 1961, 40, 2026.

39. Haas, E., and H. Goldblatt. Renin content of kidneys in experimental renal and human essential hypertension. Amer. J. Physiol. 1959, 197, 1103.

40. Genest, J., E. Koiw, W. Nowaczýnski, and G. Leboeuf. Further studies on urinary aldosterone in human arterial hypertension. Proc. Soc. exp. Biol. (N. Y.) 1958, 97, 676.

41. Laragh, J. H., S. Ulick, W. Januszewicz, Q. B. Deming, W. G. Kelly, and S. Lieberman. Aldosterone secretion and primary and malignant hypertension. J. clin. Invest. 1960, 39, 1091.

42. Leutscher, J. A., Jr., and B. J. Axelrad. Increased aldosterone output during sodium deprivation in normal man. Proc. Soc. exp. Biol. (N. Y.) 1954, 87, 650.

43. Pitcock, J. A., P. M. Hartroft, and L. N. Newmark. Increased renal pressor activity, (renin) in sodium deficient rats and correlation with juxtaglomerular cell granulation. Proc. Soc. exp. Biol. (N. Y.) $1959,100,868$

44. Rosnagle, R. S., and G. L. Farrell. Alterations in electrolyte intake and adrenal steroid secretion. Amer. J. Physiol. 1956, 187, 7.

45. Lobban, M. C. The entrainment of circadian rhythms in man. Cold Spr. Harb. Symp. quant. Biol. 1960 , 25,325 .

46. Tobian, L. Interrelationship of electrolytes, juxtaglomerular cells and hypertension. Physiol. Rev. 1960, 40, 280. 